\title{
The Mediating Effects of Mother-Teacher Communication Attitudes and Frequency on the Relationship between Maternal Parenting Efficacy and Young Children's Social Competence
}

\author{
Jiyoung Lee ${ }^{1}$, Jeehee Baek², Jihyun Sung ${ }^{1}$ \\ Department of Child Psychology \& Education, Sungkyunkwan University, Seoul, Korea ${ }^{1}$ \\ Department of Child Welfare, Seoul Cyber University, Seoul, Korea \\ 어머니의 양육효능감과 유아의 사회적 유능감의 관계에서 \\ 어머니-유아교사 간 의사소통 태도와 빈도의 매개효과 \\ 이지영 ${ }^{1}$, 백지희 $\left.\right|^{2}$, 성지현 ${ }^{1}$ \\ 성균관대학교 아동·청소년학과 ${ }^{1}$ 서울사이버대학교 아동복지전공 ${ }^{2}$
}

Objective: This study aimed to explore the differences in mother-teacher communication attitudes and frequency according to maternal working status and to investigate the mediation effect of mother-teacher communication attitudes and frequency on the relationship between maternal parenting efficacy and young children's social competence.

Methods: Participants comprised two hundred and thirty mothers and their children, aged 4-5 years, selected by age proportional allocation sampling. Mothers were requested to complete three questionnaires: a scale to measure parental attitudes and frequency of communication toward caregiver, a scale for parenting efficacy, and a scale to measure young children's social competence.

Results: Mother-teacher communication attitudes varied depending on mothers' working status. After controlling for working status, mothers' communication attitudes partially mediated the relationships between maternal parenting efficacy and young children's social competence.

Conclusion: In mediation analysis, mother-teacher communication attitudes showed an important role in enhancing the social competence of young children. This result implies that the ways to enhance mothers' communication with teachers should be supported and teachers should be encouraged to seek for opportunities to have informative communication.

Keywords: working mothers, mother-teacher communication, communicative attitudes and frequency, parenting efficacy, social competence$$
\text { 서론 }
$$

가정과 유아교육기관은 유아의 발달에 주요하게 영향을 미

Corresponding Author: Jihyun Sung, Department of Child Psychology and Education, Sungkyunkwan University, 25-2 Sungkyunkwan-ro, Jongno-gu, Seoul, Korea

E-mail: sungjh@skku.edu
}

치는 인접 환경이다(Kikas, Lerkkanen, Pakarinen, \& Poikonen, 2016). 두 환경체계가 상호 협력적이고 보완적인 관계가 되 었을 때 유아의 성장과 발달이 긍정적으로 이루어질 수 있다

(C)The Korean Association of Child Studies

This is an Open Access article distributed under the terms of the Creative Commons Attribution Non-Commercial License (http:// creativecommons.org/licenses/by-nc/4.0) which permits unrestricted noncommercial use, distribution, and reproduction in any medium, provided the original work is properly cited. 
(Bronfenbrenner, 1979). 특히, 부모가 교사와 협력하는 것의 필요성을 느끼고 자녀의 교육과정에 참여할 때, 자녀의 발달 에 긍정적인 영향을 미치게 된다(Peet, Powell, \& O’ Donnel, 1997). Hoover-Dempsey와 Sandler (1997)는 부모가 자녀교육 에 참여하는데 영향을 미치는 원인을 분석하면서, 부모가 양 육효능감이 높은 경우 자신이 노력을 한다면 자녀의 발달에도 긍정적인 영향력을 미칠 것이라는 믿음이 높기 때문에 다양한 형태의 부모참여도 함께 높아진다고 하였다.

양육효능감은 Bandura (1977)의 자기효능감(self-efficacy) 이 론을 바탕으로 어떠한 부분에 초점을 두느냐에 따라 다양하게 정의된다. 부모의 신념 및 판단, 여러 상황에 대처할 수 있는 능력, 양육과 관련한 과제를 수행할 수 있는 정도, 양육에서 발 생하는 특정 상황에서의 문제해결 등 양육효능감의 어떤 측면 을 어떻게 고려하는가에 따라 양육효능감에 대한 정의가 다양 하게 나타난다(De Montigny \& Lacharite, 2005). 여러 연구들을 종합하였을 때, 어머니의 양육효능감은 어머니 자신의 역할에 대한 자신감을 의미하며, 양육에서 나타날 수 있는 문제 상황 이나 어려움도 스스로 관리할 수 있다고 여기는 믿음을 의미 한다(Baek, 2017; Coleman \& Karraker, 2003; J.-Y. Lee, 2009; K. H. Lee \& Seo, 2012; Teti \& Gelfand, 1991).

양육효능감이 높은 부모들은 긍정적인 양육행동을 하고 자 녀에게 지원을 더욱 많이 한다는 것으로 알려져(Jang \& Kim, 2011; Teti \& Gelfand, 1991) 양육의 질을 결정하는 요인 중 하 나로 꼽히고 있다(Chung, Kim, \& Ha, 2012). 또한 양육효능감 이 높은 어머니들은 부모로서의 역할을 더욱 적극적으로 수행 하기 때문에(M. S. Kim \& Moon, 2005; Mondell \& Tyler, 1981), 자녀의 유아교육기관과도 긴밀한 유대를 형성하고, 유아교육 기관에 의사결정자, 지원자, 교사보조자, 기관방문자 등의 역 할을 수행하는 데에도 자신감을 가지게 된다(Jones \& Prinz, 2005; Song \& Hwang, 2013).

유아교육기관의 부모참여 형태 중 부모와 유아교사 간의 의사소통은 부모와 유아교사 서로 간에 주고받는 대화로 정의 할 수 있으며(M. J. Lee \& Moon, 2008), 부모와 유아교사가 동 반자적 관계를 형성하고 서로를 이해할 수 있는 효과적인 방 안이다(Chang \& Hong, 2005). 양육효능감이 높은 어머니들은 유아교육기관에 적극적인 지원자로서의 역할을 하므로(Jones $\&$ Prinz, 2005), 교사와의 의사소통 가치를 이해하고 활발하게 교사와의 의사소통에 참여할 것으로 가정해 볼 수 있다. Song 과 Hwang (2013)의 연구에서는 부모참여의 하위요인으로 조 사된 '기관과 가정의 의사소통'과 어머니의 양육효능감이 정 적인 상관관계가 있다고 보고하였다. 그러나 의사소통의 양적
인 측면(빈도)과 질적인 측면(태도)을 구분하여 어머니의 양 육효능감과의 관계를 살펴본 연구는 없다.

어머니-유아교사 간의 의사소통에 관한 연구들(Powell, 1977; Wee, 2000; Wertheim, 1994)은 의사소통 빈도와 의사소통 태도 를 기본 요소로 꼽는다. 의사소통 빈도란 의사소통의 유형과 주제, 방법 등의 측면에서 어머니와 교사가 얼마나 빈번하게 의 사소통을 하는 가를 의미하며, 의사소통 태도는 어머니가 의사 소통과 교사에 대해 갖는 만족도와 중요도에 대한 인식 정도를 뜻한다(Wertheim, 1994). 어머니가 유아교사 간의 의사소통 과 정에 만족하지 못하고 의사소통의 중요성을 인식하지 못하면 의사소통의 어려움을 야기하는 것으로 알려져(Koo, 2001; Roh, 2012) 어머니가 긍정적인 의사소통 태도를 지니는 것은 유아교 사와 어머니 간의 협력적인 의사소통에 중요한 요소라고 할 수 있다(Endsley \& Minish, 1991; Fan, 1985; J. A. Lee, 2012).

어머니-유아교사 간 의사소통에서 빈도와 태도는 서로 간 의 깊은 관련성이 있는데, Gotts와 Purnell (1986)은 유치원 프 로그램에 적극적으로 참여하는 부모일수록 기관에 더욱 소속 감을 느끼게 된다고 하였고, 의사소통을 빈번하게 하는 부모 일수록 의사소통을 중요하게 생각하며 긍정적인 의사소통 태 도를 가지고 있는 것으로 나타났다(Powell, 1977; Pollman \& Weinstein, 1983). 특히 유아교육기관 방문이나 부모회와 같은 부모참여를 통해 이루어진 어머니와 유아교사의 의사소통은 어머니들의 의사소통 인식에 긍정적인 영향을 주는 것으로 밝 혀졌다(I. J. Bae \& Wee, 2004; J. A. Lee, 2012).

Epstein (1987)의 '가족-학교 간 연계(family-school connection)' 이론에 따르면 부모가 교사와 공통의 목표를 갖고 원활한 의사 소통을 통해 자녀 교육에 참여할 때, 아동의 발달을 긍정적으로 이끌 수 있다고 하였다. 선행연구들에서도 어머니는 유아교사 와의 의사소통을 통하여 어머니로서 자신을 이해하고 긍정적 으로 느끼게 되고, 유아교사는 가정에서 생활하는 유아에 대한 정보를 얻게 되어 유아에게 적절한 교수.학습을 제공하고 이는 유아의 발달과 학습에 도움이 되는 것으로 밝혀졌다(El Nokali, Bachman, \& Votruba-Drzal, 2010; Galino \& Sheldon, 2012; Gelfer, 1991; Radin, 1972; S.-Y. Sung, 2007; Sutherland, 1991). 유아의 발 달 영역 중에서도 유아의 사회적 능력은 어머니와 교사 간의 긍정적인 의사소통을 통하여 각각이 가지고 있는 가치와 양육 태도를 공유하여 유아에게 안정되고 일관성 있는 환경이 제공 될 때 더욱 발달하게 된다(Ainslie, 1990; Fan, 1985; Pollman \& Weinstein, 1983).

예를 들어, 어머니-유아교사 간 의사소통이 빈번히 이루어지 면 유아의 또래 간 상호작용이 긍정적으로 증가하고(Smith \& 
Hubbard, 1988), 유아의 사회.정서 발달이 원만하게 이루어지도 록 지원하는 것으로 나타났다(I. J. Bae \& Wee, 2004; Fan, 1985; K. O. Lee \& Lee, 1998). 또한 유아교사가 다양한 방법을 사용하여 부모와의 의사소통을 잘 할수록 유아의 또래 놀이행동을 증진 시키며, 나아가 교사와 유아의 부정적인 상호작용과 유아의 또 래 놀이행동의 관계도 중재해 주는 것으로 밝혀졌다(Y.-H. Kim $\&$ Park, 2014). 어머니가 교사와의 의사소통에 대해서 호의적인 태도를 지니는 것도 유아의 높은 사회적 능력과 관련이 있는 것 으로 밝혀져(I. J. Bae \& Wee, 2004; Smith \& Hubbard, 1988), 어 머니와 교사의 의사소통 태도와 빈도 두 변인은 모두 다른 사람 과 관계를 맺고 유지하는 전반적인 능력인 유아의 사회적 유능 감(Katz \& McClellan, 1997; H. M. Kim \& Doh, 2004; Provost \& LaFreniere, 1991)과 밀접한 관련이 있는 것을 알 수 있다.

유아의 사회적 유능감은 어머니의 양육효능감과도 높은 관련이 있는 것으로 알려져 있다. 어머니의 양육효능감이 높 으면 바람직한 양육행동을 하고, 자녀와 긍정적인 상호작용 을 하게 됨으로써 유아의 신체적 - 정서적 - 심리적 발달을 긍 정적으로 이끌 수 있다(Coleman \& Karraker, 2003; H. M. Kim $\&$ Doh, 2004; J. Sung, 2018). 구체적으로, 어머니의 높은 양육 효능감은 유아가 자신에 대한 긍정적인 자아개념을 형성함으 로써 사회적 유능감을 높이고 원만한 사회적 상호작용을 통 해 대인관계를 잘 형성할 수 있도록 이끈다고 하였다(Kwon, 2017; I.-H. Lee, Choi, \& Song, 2013; Yeon \& Choi, 2017).

이와 같이 유아교육기관에 자녀를 보내는 과정에서 양육효 능감이 높은 어머니는 부모로서 자신의 역할의 중요성을 인 식하여 유아교사와 긴밀한 관계를 구축하고자 노력할 것이 고, 이는 자녀의 긍정적인 사회성 발달에까지 영향을 미칠 것 이다. 따라서 어머니의 유아교사와의 의사소통에 대한 태도와 빈도는 어머니의 양육효능감과 유아의 사회적 유능감 간의 관 계에 영향을 줄 것으로 예측된다.

한편, 취업모 자녀의 경우 취학 시작 연령은 낮아지고 있지 만 기관에 머무르는 시간은 증가하고 있어 교사와의 긴밀한 연계가 무엇보다 중요하다(A. R. Kim, 2010). 취업모들은 자녀 를 직접 양육하지 못하고 자녀와 함께 보내는 시간이 적다는 사실에 대한 죄책감과 불안감 때문에 부모역할의 중요성을 더 강하게 인식하고 있으며(Huston, \& Aronson, 2005; Y.-H Kim, 2004), 양육에 관련한 교육이나 정보의 필요성도 크게 느낀다 고 보고되었다(H. L. Kim, 2003; Y. S. Park, 2006). 취업모의 경 우, 비취업모보다 등.하원시에 원장이나 교사와 대화를 더 많 이 하려는 경향을 보이기도 하며(Moon \& Choi, 2009), 비취업 모에 비해 시간적인 여유가 없기 때문에 쪽지나 게시판을 이
용하여 의사소통을 자주하는 것으로 나타났다(Jung, 2006; A. R. Kim, 2010). 그러나 비취업모가 취업모보다 여러 가지 주제 에 대해 교사와 의사소통을 더욱 빈번하게 하고 있다고 보고 된 연구(J. A. Lee, 2012; Yu \& Ahn, 2010)들도 있어 취업여부에 따른 어머니와 유아교사 간의 의사소통의 태도와 빈도에 차이 가 있는지 살펴보고자 한다.

본 연구의 목적은 어머니의 취업여부에 따라 어머니-유아 교사의 의사소통 태도와 빈도에 차이가 나타나는지 확인하고, 어머니의 취업여부를 통제한 후 어머니의 양육효능감과 어머 니-유아교사 간 의사소통의 태도와 빈도, 유아의 사회적 유능 감 간의 관계를 분석하여 어머니-유아교사 간의 의사소통 태 도와 빈도가 어머니의 양육효능감과 유아의 사회적 유능감과 의 관계에서 어떠한 역할을 하는지 알아보는 것이다. 본 연구 의 결과는 어머니의 양육효능감이 자녀의 긍정적인 사회적 발 달에 영향을 미치는 주요 변인임을 재확인하고, 부모의 양육 과 자녀 발달 사이에 유아교사와의 의사소통이 주는 의미를 새롭게 탐색해보는 기회를 제공할 것이다. 또한 유아교육기관 에서 유아교사와 부모 간의 의사소통을 효율적으로 진행하기 위한 방향성과 보완점을 제시하는 자료가 될 것이다. 본 연구 에서 선정한 연구문제는 다음과 같다.

\section{연구문제 1}

어머니의 취업여부에 따라 어머니-유아교사 의사소통 태도와 빈도에 차이가 있는가?

\section{연구문제 2}

어머니의 양육효능감, 어머니-유아교사 의사소통 태도와 빈도 및 유아의 사회적 유능감 간의 관계는 어떠한가?

\section{연구문제 3}

어머니의 양육효능감과 유아의 사회적 유능감의 관계에서 어 머니-유아교사 의사소통 태도와 빈도는 매개 역할을 하는가?

\section{연구방법}

\section{연구대상}

본 연구는 광주광역시 소재의 유치원 10 개소를 이용하는 만 4 세와 만 5세 사이의 유아와 그들의 어머니 230명을 대상으로 실시하였다. 연구대상의 표집은 광주광역시의 5 개 행정구역 
Table 1

Socio-Demographic Features of Subjects

\begin{tabular}{|c|c|c|c|c|c|}
\hline Variables & Categories & $n(\%)$ & Variables & Categories & $n(\%)$ \\
\hline \multirow[t]{5}{*}{ Mothers' age } & Below 30s & $16(7.0)$ & Mothers' education level & Middle school or less & $3(1.3)$ \\
\hline & Over 31-under 35 & $130(56.5)$ & & High school & $71(30.9)$ \\
\hline & Over 36-under 40 & $69(30.0)$ & & Vocational college & $70(30.4)$ \\
\hline & Over 41-under 45 & $13(5.7)$ & & College & $77(33.5)$ \\
\hline & Over 46-under 50 & $2(0.9)$ & & Graduate school and above & $9(3.9)$ \\
\hline \multirow[t]{2}{*}{ Mothers' working status } & Working & $115(50.0)$ & Sex of children & Boy & $117(50.9)$ \\
\hline & Non-working & $115(50.0)$ & & Girl & $113(49.1)$ \\
\hline \multirow[t]{4}{*}{ Age of children } & 4 years old & $115(50.0)$ & Number of children & $1 \mathrm{kid}$ & $25(10.9)$ \\
\hline & 5 years old & $115(50.0)$ & & 2 kids & $148(64.3)$ \\
\hline & & & & 3 kids & $47(20.4)$ \\
\hline & & & & 4 kids & $10(4.3)$ \\
\hline
\end{tabular}

Note. $N=230$.

에 거주하는 유아의 연령별 비율에 관한 통계청 자료를 바탕 으로 각 행정구의 만 4-5세 유아를 비례할당표집하였다. 연구 대상 유아는 만 4세 115명(50\%), 만 5세 115명(50\%)이었으며, 남아 117 명(50.1\%)과 여아 113명(49.1\%)으로 구성되었다. 연 구대상 어머니의 연령분포는 만 23 50세로 평균 연령은 34.9 세였으며, 취업모가 115 명 $(50 \%)$, 미취업모가 115 명(50\%)으 로 조사되었다. 어머니의 학력은 중졸이하 3 명 $(1.3 \%)$, 고졸 71 명(30.9\%), 전문대졸 70명(30.4\%), 대학졸 77명(33.5\%), 대학 원 이상이 9명(3.9\%)이었다(Table 1).

\section{연구도구}

\section{어머니의 양육효능감}

어머니의 양육효능감은 Meunier와 Roskam (2009)이 개발한 Echelle Globale du Sentiment de Coptetence Parentals [EGSCP] 를 우리나라 영·유아 어머니를 대상으로 J. Sung과 Baek (2011) 이 타당화한 한국판 양육효능감 척도(K-EGSCP)를 사용하여 측정하였다. 본 연구에서는 $\mathrm{EGSCP}$ 의 구성 요인 중 양육효능 감 요인을 사용하였으며, 양육효능감 요인은 훈육, 놀이, 애정, 일상체계 조직, 교육의 5 가지 영역으로 구성되며 총 22개 문 항이다. 문항은 6점 Likert 척도로 평가하였으며 응답자인 어 머니의 평상시 모습에 비추어 자신의 행동을 가장 잘 설명하 고 있는 정도에 따라 전혀 아니다(1점)에서부터 매우 그렇다(6 점)까지로 응답하게 하였다. 점수가 높을수록 어머니가 양육 의 제 영역에서 효능감을 높게 가지고 있음을 의미한다. 전체
척도의 신뢰도는 Cronbach's $\alpha$ 계수 .89이었다.

$$
\text { 어머니의 의사소통 태도와 빈도 }
$$

어머니의 의사소통 태도와 빈도는 Wertheim (1994)이 제 작한 의사소통 태도 척도(Parental Attitude Toward Caregiver Communication [PATCC])를 Wee (2000)가 번안하여 사용한 척도로 측정하였다. 어머니의 의사소통 태도는 의사소통 만족 도(6문항), 자녀양육/유아발달과 가족 정보에 대한 논의(10문 항), 의사소통의 가치에 대한 인식(9문항), 교사에 대한 인식(7 문항), 의사소통의 장점에 대한 인식(7문항)의 5 개 요인, 총 39 문항으로 구성되어있다. 각 문항은 전혀 그렇지 않다(1점)에 서부터 매우 그렇다(6점)까지의 6점 Likert 척도로 평가되었으 며 점수가 높을수록 어머니가 유아교사와의 의사소통에 대해 긍정적인 태도를 가지고 있음을 의미한다. 전체 척도의 신뢰 도는 Cronbach's $\alpha$ 계수 89 이었다.

어머니의 의사소통 빈도는 유아교육 전문가 3 인의 조언을 바탕으로 질문지의 일부 수정하여 측정하였다. 의사소통 빈도 관련 질문은 주제별 의사소통 빈도와 유형별 의사소통 빈도의 2 개 하위 요인으로 구성되어 있으나, 본 연구에서는 어머니유아교사 간에 얼마나 자주 의사소통이 일어나는가를 측정하 기 위하여 유형별 의사소통 빈도 문항을 사용하였다. 기존 척 도의 문항은 부모가 유아교사와 의사소통을 하는 방법(예: 등. 하원시, 전화, 기관방문, 부모상담, 게시판이나 쪽지, 가정방 문)에 따른 6 개 문항으로 구성되어 있다. 그러나 우리나라의 문화적 특성에 부합하지 않는 문항(예: 가정방문)을 제외하고 게시판이나 쪽지 문항을 현대사회에서 실사용되는 방법인 원 
아수첩과 문자 등의 메시지로 수정하여 사용하였다. 각 문항 은 6점 Likert 척도로 전혀 안한다(1점), 거의 안한다(2점), 때때 로 한다(3점), 자주 한다(4점), 거의 매일 한다(5점), 매일 한다 (6점)로 평가하였으며 점수가 높을수록 어머니가 유아교사와 의사소통을 자주 하는 것을 의미한다. 전체 척도의 신뢰도는 Cronbach's $\alpha$ 계수가 .78이었다.

\section{유아의 사회적 유능감}

유아의 사회적 유능감은 Pease, Clark와 Crase (1981), Wirth와 Pease (1983)가 개발한 Iowa Social Competency Scale-Preschool [ISCS-P]의 척도를 번안 수정한 B.-S. Park (1987)의 척도를 사 용하였다. ISCS-P는 활동성, 예민성, 안정성, 비협조성, 협조성 의 5 개 영역으로 구성되어 있고, 긍정적 사회적 행동으로 활동 성, 안정성, 협조성을 포함하며, 부정적 사회적 행동으로 예민 성과 비협조성을 포함하고 있다. 본 연구에서는 유아의 사회적 유능감을 측정하기 위하여 위 도구의 긍정적 사회적 행동에 해 당하는 활동성( 10 문항), 안정성(5문항), 협조성(6문항)의 3 개요 인 총 21 문항을 사용하였다. 각 문항은 전혀 그렇지 않다(1점) 에서부터 매우 그렇다(6점)까지의 Likert 척도로 평가되었으며 점수가 높을수록 유아의 사회적 유능감이 높은 것을 의미한다. 전체 척도의 내적합치도는 Cronbach's $\alpha$ 계수 .89이었다.

\section{연구절차}

본 조사를 시작하기 전 유아교육 전문가를 대상으로 척도와 설문지에 대한 사전조사를 실시하여 문항의 내용을 검토하였 다. 본 조사는 비례할당표집된 기관을 대상으로 사전에 연락 을 취한 후 연구 목적과 방법을 전달하고, 어머니의 연구 참여 에 대한 동의를 구한 후 실시하였다. 전체 설문지의 작성 시간 은 약 15-20분이 소요되었고, 회수된 설문지 중 응답이 충분하 지 못하거나 누락된 설문지를 제외하여 최종적으로 230 부가 자료 분석에 사용되었다.

\section{자료분석}

본 연구의 자료는 SPSS 18.0 을 이용하여 다음과 같이 분석하 였다. 어머니의 취업여부에 따른 어머니-유아교사 간의 의사 소통 태도와 빈도의 차이는 t검증을 실시하였다. 차이검증 결 과를 고려하여 어머니의 취업여부를 통제한 상태에서 어머니 의 양육효능감, 어머니-유아교사 간 의사소통 태도와 빈도, 유
아의 사회적 유능감 간의 관계를 알아보기 위해 편상관분석을 실시하였다. 마지막으로 어머니의 취업여부를 통제한 상태에 서 어머니-유아교사의 의사소통 태도와 빈도가 어머니의 양 육효능감과 유아의 사회적 유능감의 관계를 매개하는지를 살 펴보기 위하여 Baron과 Kenny (1986)가 제안한 매개효과 검증 절차를 사용하였다.

\section{연구결과}

\section{어머니의 취업여부에 따른 어머니-유아교사의 의사소통 태도와 빈도의 차이}

어머니-유아교사의 의사소통 태도와 빈도가 어머니의 취업여 부에 따라 어떠한 차이가 있는지 살펴보기 위하여 t검증을 실 시한 결과(Table 2), 전반적인 어머니-유아교사의 의사소통 태 도와 의사소통 빈도의 일부 하위 요인에서 유의미한 차이가 있는 것으로 나타났다.

먼저, 취업을 한 어머니는 취업을 하지 않은 어머니보다 유 아교사와의 의사소통에 대한 태도의 총점이 유의하게 높은 것 으로 나타났다 $(t=2.89, p<.01)$. 하위요인별로 살펴보면, 어머 니-유아교사의 의사소통의 태도 중 의사소통만족도 $(t=2.15$, $p<.05)$ 와 양육발달정보논의 $(t=2.56, p<.05)$, 의사소통가치 인식 $(t=2.07, p<.05)$, 교사에 대한 인식 $(t=2.74, p<.01)$, 의사 소통장점인식 $(t=2.00, p<.05)$ 하위요인 모두에서 취업을 한 어머니가 취업을 하지 않은 어머니보다 의사소통 태도가 높은 것으로 나타났다.

의사소통 빈도의 총점은 취업을 한 어머니가 $(M=3.30)$ 취 업을 하지 않은 어머니보다 $(M=3.20)$ 평균이 높았으나 통계적 으로 유의한 차이는 아니었다 $(t=1.02, n s)$. 그러나 의사소통 빈 도의 하위요인들 중, 기관방문 $(t=2.02, p<.05)$ 과 부모상담 $(t=$ $2.41, p<.05)$ 을 통한 의사소통 빈도는 취업을 한 어머니가 취 업을 하지 않은 어머니보다 유의하게 높은 것으로 나타났다.

\section{어머니의 양육효능감, 어머니-유아교사의 의사소통 태도와 빈도 및 유아의 사회적 유 능감 간의 관계}

연구문제 1 의 분석결과, 어머니의 취업여부에 따라 유의미한 차이가 발견됨에 따라 어머니의 취업 여부를 통제하고, 어머 니의 양육효능감, 어머니-유아교사의 의사소통 태도와 빈도 
Table 2

Group Differences in Communication Attitudes and Frequency Between Working Mother and Unemployed Mother

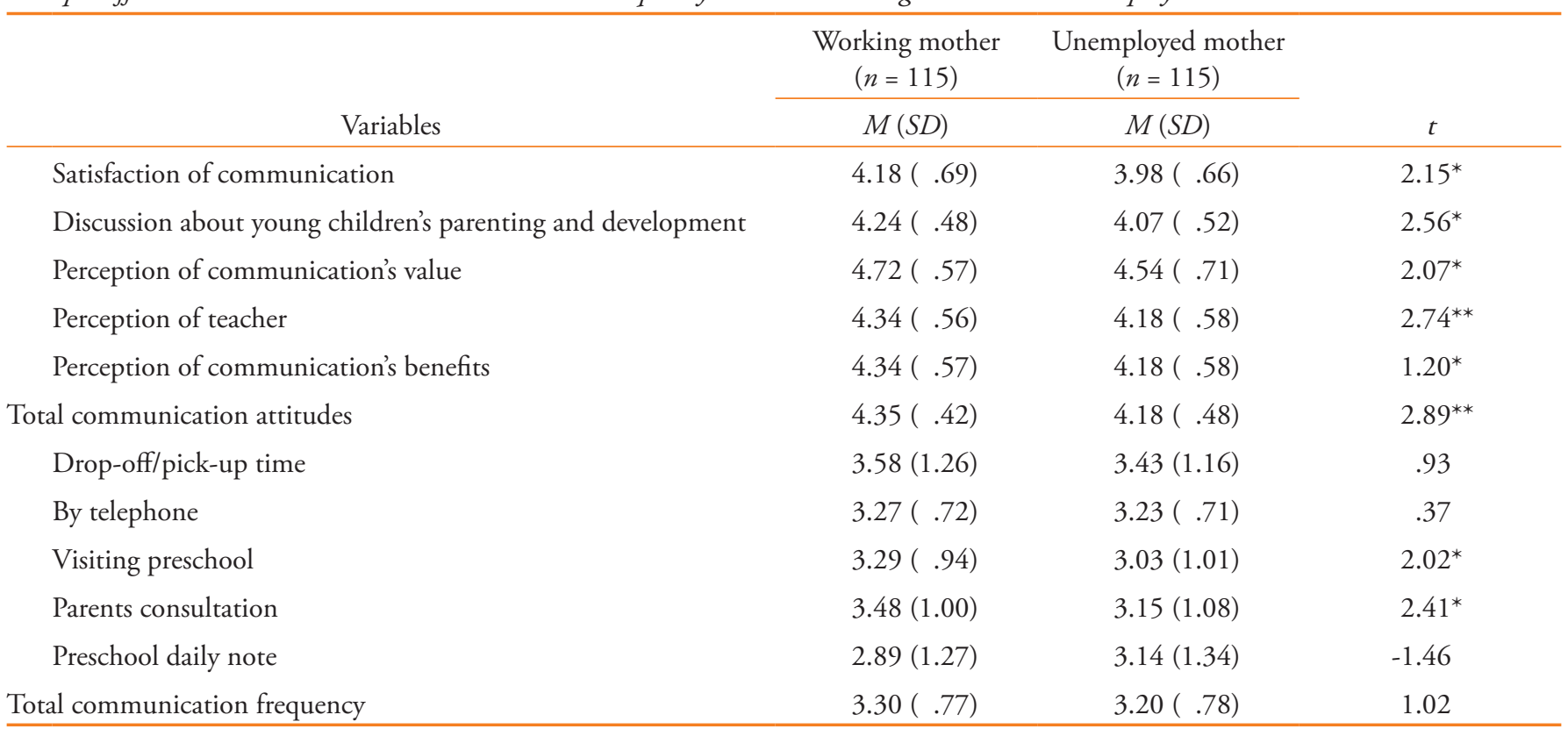

Note. $N=230$.

${ }^{*} p<.05 .{ }^{* *} p<.01$.

Table 3

Mean, Standard Deviation, and Partial Correlation Coefficients of Variables

\begin{tabular}{|c|c|c|c|c|c|}
\hline Variables & $M(S D)$ & 1 & 2 & 3 & 4 \\
\hline 1. Maternal parenting efficacy & $4.20(0.60)$ & 1 & & & \\
\hline 2. Communication attitudes & $4.27(0.46)$ & $.41^{* * *}$ & 1 & & \\
\hline 3. Communication frequency & $3.25(0.77)$ & .11 & $.42^{* * *}$ & 1 & \\
\hline 4. Children's social competence & $12.63(1.41)$ & $.46^{* * *}$ & $.45^{* * *}$ & $.16^{*}$ & 1 \\
\hline
\end{tabular}

Note. $N=230$.

${ }^{*} p<.05 .{ }^{* * *} p<.001$.

및 유아의 사회적 유능감의 관계를 살펴보았다. 변인들 간의 편상관계수를 산출한 결과는 다음과 같다(Table 3).

어머니의 양육효능감은 어머니-유아교사의 의사소통 태도 $(r=.41, p<.001)$ 와 유의한 상관관계가 있는 것으로 나타났고, 유아의 사회적 유능감 $(r=.46, p<.001)$ 과도 유의한 정적 상관 을 갖는 것으로 나타났다. 또한 어머니-유아교사의 의사소통 태도는 어머니-유아교사의 의사소통 빈도 $(r=.42, p<.001)$ 와 유의한 정적 상관관계가 나타났으며, 유아의 사회적 유능감 $(r=.45, p<.001)$ 과도 유의한 정적 상관관계가 있는 것으로 나 타났다. 마지막으로 어머니-유아교사의 의사소통 빈도도 유 아의 사회적 유능감 $(r=.16, p<.05)$ 과 유의한 정적 상관관계 가 있는 것으로 나타났다.
어머니의 양육효능감과 유아의 사회적 유능감 과의 관계에서 어머니-유아교사의 의사소통 태도와 빈도의 매개 역할

어머니의 취업 여부를 통제한 상태에서 어머니의 양육효능감 과 유아의 사회적 유능감의 관계에서 어머니와 유아의 의사소 통 태도와 빈도가 매개 역할을 하는지 알아보기 위해 Baron과 Kenny (1986)가 제안한 회귀분석조합을 통한 매개변인 분석 을 실시하였다. 결과를 분석하기에 앞서 독립변인들 간의 다 중공선성의 가능성을 살펴보았다. VIF 지수는 $1.118 \sim 1.313$, 공차한계(Tolerance)는 .762 .895의 범위로 허용 가능한 정도 로 나타나 독립변인들 간 다중공선성의 위험은 배제된 것으로 
Table 4

Mediating Effects of Communication Attitudes on the Relationship Between Maternal Parenting Efficacy and Young Children's Social Competence

\begin{tabular}{|c|c|c|c|c|c|c|}
\hline Model & Variables & $B(S E)$ & $\beta$ & $R^{2}$ & $\triangle R^{2}$ & $F$ \\
\hline \multirow[t]{2}{*}{ Model 1} & Maternal working status $\rightarrow$ Communicative attitudes & $-.14(.06)$ & $-.16^{*}$ & .20 & & $27.68^{* * *}$ \\
\hline & Maternal parenting efficacy $\rightarrow$ Communicative attitudes & $.31(.05)$ & $.40^{* * *}$ & & $.16^{* * *}$ & \\
\hline \multirow[t]{2}{*}{ Model 2} & Maternal working status $\rightarrow$ Preschoolers' social competence & $-.29(.17)$ & -.10 & .22 & & $32.24^{* * *}$ \\
\hline & Maternal parenting efficacy $\rightarrow$ Preschoolers' social competence & $1.06(.14)$ & $.45^{* * *}$ & & $.20^{* * *}$ & \\
\hline \multirow[t]{3}{*}{ Model 3} & Maternal working status $\rightarrow$ Preschoolers' social competence & $-.15(.16)$ & -.05 & .30 & & $32.58^{* * *}$ \\
\hline & Maternal parenting efficacy $\rightarrow$ Preschoolers' social competence & $.76(.14)$ & $.32^{* * *}$ & & & \\
\hline & Communicative attitudes $\rightarrow$ Preschoolers' social competence & $.97(.19)$ & $.32^{* * *}$ & & $.08^{* * *}$ & \\
\hline
\end{tabular}

Note. $N=230$.

${ }^{*} p<.05 .{ }^{* * *} p<.001$.

확인되었다. 매개변인 분석 결과, 어머니-유아교사의 의사소 통 태도와 빈도 중, 어머니-유아교사의 의사소통 태도만이 어 머니의 양육효능감과 유아의 사회적 유능감의 관계를 부분 매 개하는 것으로 나타났고, 그 결과는 다음과 같다(Table 4).

연구모형을 살펴보면, 모델 1 에서 어머니의 취업여부를 통 제하였을 때, 어머니의 양육효능감이 의사소통 태도에 미치 는 영향의 설명력은 $16 \%$ 였다. 통제변수인 어머니의 취업여부 와 독립변수인 어머니의 양육 효능감이 매개변수인 어머니-유 아교사의 의사소통 태도 분산의 $20 \%$ 를 설명하였고, 어머니 양 육효능감의 회귀계수도 통계적으로 유의하였다 $(\beta=.40, p<$ .001). 모델 2에서 어머니의 취업여부를 통제하였을 때, 어머니 의 양육효능감이 유아의 사회적 유능감에 미치는 영향의 설명 력은 $20 \%$ 였다. 통제변수인 어머니의 취업여부와 독립변수인 어머니의 양육효능감이 종속변수인 유아의 사회적 유능감 분 산의 $22 \%$ 를 설명하였고, 어머니의 양육효능감의 회귀계수는 통계적으로 유의하였다 $(\beta=.45, p<.001)$. 모델 3에서 통제변 수인 어머니의 취업여부와 독립변인인 어머니의 양육효능감, 매개변인인 어머니-유아교사 의사소통 태도는 종속변수인 유 아의 사회적 유능감의 분산 $30 \%$ 를 설명하였다. 어머니의 취업 여부와 양육효능감을 통제하였을 때, 어머니-유아교사의 의사 소통 태도가 유아의 사회적 유능감에 미치는 영향의 설명력은 $8 \%$ 증가하였다. 어머니의 의사소통 태도가 추가된 모델 3에서 는 어머니의 양육효능감이 유아의 사회적 유능감에 미치는 영 향력 $(\beta=.32, p<.001)$ 이 모델 2와 비교하였을 때보다 감소하여 $(\beta=.45 \rightarrow .32)$ 어머니-유아교사의 의사소통 태도의 부분매개 효과가 검증되었다. Sobel test를 실시하여 매개효과의 유의성 을 검증한 결과, $z$ 값이 $4.07(p<.001)$ 로 통계적으로 유의미한 것으로 나타나 부분매개효과의 유의성이 확인되었다.

\section{논의 및 결론}

본 연구는 어머니의 취업여부에 따른 어머니-유아교사의 의사 소통 태도 및 빈도에서의 차이를 확인하고, 어머니의 양육효능 감과 유아의 사회적 유능감 간의 관계에서 어머니-유아교사 간 의 의사소통 빈도와 태도의 매개 역할을 살펴보고자 하였다. 본 연구에서 나타난 결과를 요약하고 논의하면 다음과 같다.

첫째, 어머니의 취업여부에 따른 어머니-유아교사의 의사 소통 태도와 빈도를 분석한 결과, 취업을 한 어머니가 취업을 하지 않은 어머니보다 유아교사와의 의사소통에 긍정적인 태 도를 가지고 있는 것으로 나타났다. 어머니가 직장을 가지고 있는 경우, 자녀와 함께 보내는 시간이 미취업모에 비하여 상 대적으로 적기 때문에 부모 역할을 보다 중요하다고 생각한 다(Y.-H. Kim, 2004; Y. S. Park, 2006). 또한 취업을 한 어머니가 양육에 관한 교육의 필요성도 상대적으로 더 많이 느낀다고 선행연구들은 보고하고 있다(Y.-H. Kim, 2004; Marks, Huston, Johnson, \& MacDermid, 2001; Y. S. Park, 2006). 본 연구의 결과 에서도 취업을 한 어머니는 스스로의 역할이 부족하다고 생각 하고 이를 보완할 수 있는 방안으로서 자녀를 담당하는 유아 교사와의 의사소통을 중요하게 생각하고 긍정적인 태도를 보 이는 것으로 볼 수 있다.

유아교사와 의사소통을 하는 총 빈도에서는 취업모와 미취 업모의 차이가 나타나지 않았다. 흔히 취업모의 경우, 일을 하 고 있다는 제한적인 상황 때문에 유아교사와의 의사소통이 상 대적으로 적을 것으로 생각할 수 있지만(Sim, 2013), 유아교사 와 의사소통을 취할 수 있는 방법이 다양해지면서 취업모와 미취업모 간의 의사소통 총 빈도는 유사한 것으로 볼 수 있다. 그러나 의사소통을 하는 구체적인 방법에 따라서는 차이가 나 
타났다. 취업모들은 미취업모에 비하여 '기관방문'과 '부모상 담'을 통한 어머니-유아교사의 의사소통 빈도가 더 높은 것으 로 나타났다. Ju (2002)의 연구에서도 기관에서의 실시하는 상 담에 취업모가 미취업모보다 높은 빈도로 참여한 것으로 보고 하여 본 연구의 결과와 유사하다. 일반적으로 취업모는 비취 업모보다 시간적 여유가 부족하여 기관에의 참여가 용이하지 는 않지만 부모 역할의 중요성을 더욱 강하게 인식하고 있다 (A. R. Kim, 2010; H. L. Kim, 2003). 또한 미취업모보다 양육과 부모역할에 대한 정보를 수집하는 방법이 다양하지 못하고 자 녀에 관한 정보와 자녀와 보내는 시간이 절대적으로 부족하 다고 생각하는 경향(H. Choi, 2007; N. H. Kim, Lee, Kwak, \& Park, 2013)이 있기 때문에, 기관에서 실시하는 주요 행사와 상 담에 적극적으로 참여하고 있는 것으로 볼 수 있다.

둘째, 어머니의 양육효능감, 어머니-유아교사의 의사소통 태도와 빈도, 유아의 사회적 유능감의 관계를 살펴본 결과, 어 머니의 양육효능감과 유아교사와의 의사소통에 대한 태도가 정적인 상관이 있는 것으로 나타났다. 이는 어머니가 자녀를 양육하는 것에 대해 스스로 자신감을 갖고 잘 할 수 있을 것이 라고 인지하고 있을 때, 기관이나 교사와의 의사소통에서 장 점과 가치를 발견하고 만족한다는 것을 시사한다. 양육효능감 이 높은 어머니는 유아교육기관 참여를 보다 긍정적으로 생각 하는 경향이 있다(Coleman \& Karraker, 2003; Hoover-Dempsey \& Sandler, 1997; H. M. Kim \& Doh, 2004; Kwon, 2017; Yeon \& Choi, 2017). 따라서 양육효능감이 높은 어머니는 부모참여의 한 형태인 유아교사와의 의사소통 또한 중요하게 생각한 것으 로 해석할 수 있다.

부모의 양육효능감이 높다는 것은 양육에서 자신의 역할을 구체적으로 인지하고 그 역할을 위한 준비도가 높다는 것을 의미한다(Ardelt \& Eccles, 2001). 이러한 특성은 부모로서의 역 할을 더욱 잘해내기 위한 노력으로 이어질 수 있으므로(M.-J. Kim, Doh, Shin, \& Choi, 2013), 유아교육기관과 교사와의 적 극적인 상호작용을 통하여 자녀에 대한 이해를 높이고 스스로 를 발전시키는 기회로 작용할 수 있다. 따라서 양질의 부모-유 아교사 간의 의사소통은 무엇이고 어떻게 이루어질 수 있는가 에 대해 보다 구체적으로 탐색하여 부모와 유아교사 간의 의 사소통 확장을 도모할 수 있어야 할 것이다.

한편, 어머니의 양육효능감과 의사소통의 빈도 간에는 유 의한 관계가 나타나지 않았다. 이는 어머니가 자녀를 잘 양육 할 수 있다는 믿음이 유아교사와의 의사소통 횟수의 증가 혹 은 감소와는 무관하다는 것을 보여준다. 유아교육기관에서는 부모와의 적극적인 의사소통을 위하여 소통 방법을 다양하게
하고 주기적인 의사소통 창구를 열어두기 위해 노력한다. 그 러나 본 연구의 결과처럼 양육효능감이 높은 어머니들은 의사 소통의 빈도보다는 의사소통의 가치와 장점을 인식하고 의사 소통 속에서 자녀의 발달이나 교육, 양육에 대한 논의가 이루 어지는 질적 측면을 중요하게 보고 있다는 것을 알 수 있다. 교 사가 어머니와의 의사소통을 위한 준비를 적절하게 해내지 못 하고 있다는 지적이 지속적으로 나오고 있는 만큼(M. Choi \& Park, 2004; Lawler, 1991; Wee, 2000), 부모-유아교사 간의 의사 소통이 간단한 대화와 편지 등의 의미를 벗어나 질적으로 부 모에게 도움이 되는 내용으로 구성될 수 있도록 기관과 교사 에게 충분히 안내될 필요가 있을 것이다.

어머니의 양육효능감과 어머니-유아교사의 의사소통 태 도와 빈도는 모두 유아의 사회적 유능감과 유의한 상관을 보 였다. 이러한 결과는 양육에서 부모가 높은 효능감을 가질수 록 유아의 사회.정서적 적응이 증진되고 또래를 비롯한 교사 의 평가에서도 사회적으로 유능하다는 기존의 연구들의 결과 들(Giallo, Treyvaud, Cooklin, \& Wade, 2013; Junttila \& Vauras, 2014; J. Sung, 2018; Yoon \& Sung. 2014)을 뒷받침한다. 또한 어 머니와 유아교사가 의사소통을 통해 자녀에 관한 정보를 자주 교환하고 가치 있게 여길수록 자녀가 유아교육기관과 가정에 서 일치감을 느끼고 기관에서 더욱 안정적으로 지낼 수 있도록 도와줌으로써 유아의 사회성을 기르는데 도움을 줄 수 있는 것 (I. J. Bae \& Cho, 2014; Fan, 1985; Gotts \& Purnell, 1986; Powell, 1977; Smith \& Hubbard, 1988)으로 해석할 수 있을 것이다.

마지막으로, 어머니-유아교사의 의사소통 관련 변인 중 의 사소통 태도는 어머니의 양육효능감과 유아의 사회적 유능감 간의 관계를 부분 매개하는 것으로 나타났다. 이는 어머니가 긍정적인 양육효능감을 가질수록 교사와의 의사소통에 대해 더욱 긍정적으로 생각하고, 자녀의 사회적 유능감도 함께 높 아질 수 있음을 의미한다. 그러나 어머니-유아교사의 의사소 통 빈도는 매개효과가 나타나지 않았는데 이는 어머니의 높은 양육효능감이 자녀의 긍정적인 사회성 발달에까지 이르기 위 해서는 어머니가 유아교사와 의사소통을 자주하는 것보다 의 사소통에 대해 어떤 견해를 갖고 접근하느냐가 더 중요하다는 것을 알 수 있다. 즉, 교사와의 의사소통을 필요한 것이고, 중 요하게 여길수록 어머니는 의사소통에서 자녀의 발달과 교육 에 도움이 될 수 있는 내용을 다룰 가능성이 높으며, 이를 통 해 자녀의 사회적 유능감도 함께 높일 수 있는 것으로 볼 수 있 다. 어머니와 교사의 일상적인 의사소통이 자주 일어나는 것 에 비해 의사소통의 장점에 대해 인식하지 못하고, 의사소통 의 내용에 만족하지 못하는 것으로 나타난 연구들(Eendsley \& 
Minish, 1991; Fan, 1985; J. A. Lee, 2012; Powell, 1977)에서도 강 조했듯이 어머니-유아교사 간 의사소통이 활발하게 이루어진 다고 하여도 그 질적인 측면에 만족할 수 없다면 자녀의 발달 에도 도움이 될 수 없을 것이다.

본 연구의 제한점을 토대로 후속 연구를 위한 제언을 하면 다음과 같다. 첫째, 본 연구에서는 의사소통의 빈도를 분석할 때, 방법적 측면에서의 빈도가 어떠한가에 초점을 두었다. 그 러나 어머니-교사 간 의사소통의 빈도는 의사소통의 주제나 시기 등에 따른 분석도 가능하다(Wertheim, 1994). 또한 의사 소통에서 오가는 내용에 따라 의사소통 유형(사교적, 정보적, 의사결정 등)을 구분 짓거나 혹은 의사소통의 경로(일방향과 쌍방향)등으로 다양하게 분석될 수 있다(Ghazvini \& Readdick, 1994; Winkelstein, 1981). 따라서 교사와 어머니의 의사소통이 주요한 역할을 한다는 본 연구의 결과를 바탕으로 어머니-유 아교사 간의 의사소통의 다각적 측면이 후속적으로 이루어지 기를 기대한다.

둘째, 본 연구의 대상은 유아교육기관을 이용하는 자녀를 둔 어머니를 대상으로 하고 있어 자녀의 연령층이 만 4 세와 5 세로 국한되어 있다. 또한 표집이 우리나라 대도시의 한 곳에 서만 집중적으로 이루어짐으로 인해서 지역적 특색을 반영하 고 있을 수 있다. 어머니와 유아교사 간의 관계는 교육기관에 머무는 시간이 길거나 아이의 연령에 따라 달라지는 것으로 보고되었다(Son, 2008). 따라서 만 0세에서 2세 사이의 영아를 연구대상에 포함시키거나, 어린이집을 이용하는 어머니로 연 구대상의 범위를 확대하여 본 연구의 결과와 비교하는 의미 있는 연구도 후속되기를 기대한다.

본 연구를 통하여 자녀가 기관에서 또래와 긍정적인 사회 관계를 형성하기 위해서는 근본적으로 어머니가 심리적으로 건강하고 높은 양육효능감을 가지는 것이 중요하다는 것을 확 인할 수 있었다. 그러므로 유아기 자녀를 가진 부모의 양육효 능감을 증진시킬 수 있는 양육 지원 프로그램을 지속적으로 개발하고 부모를 끓임없이 지원할 수 있는 방안을 마련하는 것은 현대 사회의 긍정적 육아를 위한 숙제이다. 뿐만 아니라, 본 연구의 결과는 어머니들이 유아교사와의 질적으로 만족스 러운 의사소통을 할 수 있을 때 자녀의 긍정적 사회적 행동들 을 증진시킬 수 있음을 시사한다. 따라서 부모가 유아교사와 의 의견 교환을 통해 자녀의 발달사항과 교실 내 활동과 같은 자녀 양육에 필요한 정보와 실질적인 도움을 얻고 유아교사와 의 의사소통을 가치 있고 만족스럽게 여길 수 있는 방안들이 지속적으로 탐구되기를 기대한다.

\section{Notes}

This article was presented at the 2017 Annual Fall Conference of the Korean Association of Child Studies.

\section{Conflict of Interest}

No potential conflict of interest relevant to this article was reported.

\section{References}

\section{In English}

Ainslie, R. C. (1990). Family and center contributions to the adjustment of infants in full-time day care. New Directions for Child and Adolescent Development, 49(1), 39-52. doi:10.1002/cd.23219904905

Ardelt, M., \& Eccles, J. S. (2001). Effects of mothers' parental efficacy beliefs and promotive parenting strategies on inner-city youth. Journal of Family Issues, 22(8), 944-972. doi:10.1177/019251301022008001

Bandura, A. (1977). Self-efficacy: Toward a unifying theory of behavioral change. Psychological Review, 84(2), 191-215. doi:10.1037/0033-295X.84.2.191

Baron, R. M., \& Kenny, D. A. (1986). The moderator-mediator variable distinction in social psychological research: Conceptual, strategic and statistical considerations. Journal of Personality and Social Psychology, 51(6), 1173-1182. doi:10.1037/0022-3514.51.6.1173

Bronfenbrenner, U. (1979). The ecology of human development by nature and design. Cambridge, MA: Harvard University Press.

Coleman, P. K., \& Karraker, K. H. (2003). Maternal self-efficacy beliefs, competence in parenting, and toddlers' behavior and developmental status. Infant Mental Health Journal, 24(2), 126-148. doi:10.1002/imhj.10048

De Montigny, F., \& Lacharité, C. (2005). Perceived parental efficacy: Concept analysis. Journal of Advanced Nursing, 49(4), 387-396. doi:10.1111/j.1365-2648.2004.03302.x

El Nokali, N. E., Bachman, H. J., \& Votruba-Drzal, E. (2010). Parent involvement and children's academic and social development in elementary school. Child Development, 81(3), 988-1005. doi:10.1111/j.1467-8624.2010.01447.x

Endsley, R. C., \& Minish, P. A. (1991). Parent-staff communication 
in day care centers during morning and afternoon transitions. Early Childhood Research Quarterly, 6(2), 119-135. doi:10.1016/0885-2006(91)90002-3

Epstein, J. L. (1987). Toward a theory of family-school connections. In K. Hurrelmann, F.-X Kaufmann, \& F. Lösel (Eds.), Social intervention: Potential and constraints (pp. 121-136). Berlin: Walter De Gruyter.

Fan, S. Y. (1985). Parent-caregiver communication and social competence of preschool-age children (Unpublished doctoral dissertation). Iowa State University, Ames.

Galindo, C., \& Sheldon, S. B. (2012). School and home connections and children's kindergarten achievement gains: The mediating role of family involvement. Early Childhood Research Quarterly, 27(1), 90-103. doi:10.1016/j.ecresq.2011.05.004

Gelfer, J. I. (1991). Teacher-parent partnerships: Enhancing communications. Childhood Education, 67(3), 164-167. do i: 10.1080/00094056.1991.10521602

Ghazvini, A. S., \& Readdick, C. A. (1994). Parent-caregiver communication and quality of care in diverse child care settings. Early Childhood Research Quarterly, 9(2), 207-222. doi:10.1016/0885-2006(94)90006-X

Giallo, R., Treyvaud, K., Cooklin, A., \& Wade, C. (2013). Mothers' and fathers' involvement in home activities with their children: Psychosocial factors and the role of parental self-efficacy. Early Child Development and Care, 183(3-4), 343-359. doi:10.1080/03004430.2012.711587

Gotts, E. E., \& Purnell, R. F. (1986). Communication: Key to school-home relations. In R. J. Griffore, \& R. P. Borger (Eds.), Child rearing in the home and school (pp. 157-200). Boston, MA: Springer.

Hoover-Dempsey, K. V., \& Sandler, H. M. (1997). Why do parents become involved in their children's education? Review of Educational Research, 67(1), 3-42. doi:10.3102/ 00346543067001003

Huston, A. C., \& Aronson, S. R. (2005). Mothers' time with infant and time in employment as predictors of motherchild relationships and children's early development. Child Development, 76(2), 467-482. doi:10.1111/j.14678624.2005.00857.x

Jones, T. L., \& Prinz, R. J. (2005). Potential roles of parental self-efficacy in parent and child adjustment: A review. Clinical Psychology Review, 25(3), 341-363. doi:10.1016/ j.cpr.2004.12.004

Junttila, N., \& Vauras, M. (2014). Latent profiles of parental self-efficacy and children's multisource-evaluated social competence. British Journal of Educational Psychology, 84(3), 397-414. doi:10.1111/bjep.12040

Katz, L. G., \& McClellan, D. E. (1997). Fostering children's social competence: The teacher's role. Washington, DC: National Association for the Education of Young Children.
Kikas, E., Lerkkanen, M.-K., Pakarinen, E., \& Poikonen, P.L. (2016). Family- and classroom-related factors and mother-kindergarten teacher trust in Estonia and Finland. Educational Psychology, 36(1), 47-72. doi:10.1080/014434 10.2014.895298

Lawler, S. D. (1991). Parent-teacher conferencing in early childhood education. Washington, DC: National Education Association.

Marks, S. R., Huston, T. L., Johnson, E. M., \& MacDermid, S. M. (2001). Role balance among white married couples. Journal of Marriage and Family, 63(4), 1083-1098. doi:10.1111/ j.1741-3737.2001.01083.x

Meunier, J.-C., \& Roskam, I. (2009). Self-efficacy beliefs amongst parents of young children: Validation of a self-report measure. Journal of Child \& Family Studies, 18(5), 495-511. doi:10.1007/s10826-008-9252-8

Mondell, S., \& Tyler, F. B. (1981). Parental competence and styles of problem solving/play behavior with children. Developmental Psychology, 17(1), 73-78. doi:10.1037/00121649.17.1.73

Pease, D., Clark, S., \& Crase, S. J. (1981). The social competency scale for preschool-age children: Its development and factorial validity. Educational and Psychological Measurement, 41(3), 851-861. doi:10.1177/001316448104100327

Peet, S. H., Powell, D. R., \& O’Donnel, B. K. (1997). Motherteacher congruence in perceptions of the child's competence and school engagement: Links to academic achievement. Journal of Applied Developmental Psychology, 18(3), 373393. doi:10.1016/S0193-3973(97)80006-8

Pollman, J., \& Weinstein, H. (1983, March). The relationship between the social and intellectual competence of young children and their mother's communication behavior with caregivers. Paper presented at a Meeting of the Southern Association of Children Under Six Research Theatre, Charleston, U.S.A.

Powell, D. R. (1977). Day care and the family: A study of interactions and congruency (Report No. ED143430). Detroit, MI: Merrill-Palmer Institute.

Provost, M. A., \& LaFreniere, P. J. (1991). Social participation and peer competence in preschool children: Evidence for discriminant and convergent validity. Child Study Journal, 21(1), 57-72.

Radin, N. (1972). Three degrees of maternal involvement in a preschool programs: Impact on mothers and children. Child Development, 43(4), 1355-1364. doi:10.2307/1127521

Smith, A. A., \& Hubbard, P. M. (1988). The relationship between parent/staff communication and children's behaviour in early childhood settings. Early Child Development and Care, 35(1), 13-28. doi:10.1080/0300443880350103

Sutherland, I. R. (1991). Parent-teacher involvement benefits everyone. Early Child Development and Care, 73(1), 121- 


\section{1. doi: $10.1080 / 0300443910730112$}

Teti, D. M., \& Gelfand, D. M. (1991). Behavioral competence among mothers of infants in the first year: The mediational role of maternal self-efficacy. Child Development, 62(5), 918-929. doi:10.1111/j.1467-8624.1991.tb01580.x

Wertheim, L. (1994). Communication patterns and communication attitudes between parents and caregivers (Unpublished doctoral dissertation). Pace University, New York.

Winkelstein, E. (1981). Day care/family interaction and parental satisfaction. Child Care Quarterly, 10(4), 334-340. doi:10. 1007/BF01160689

Wirth, S., \& Pease, D. (1983). Convergent and discriminant validity of the Iowa Social Competency Scale for preschool children. Educational and Psychological Measurement, 43(1), 305-314. doi:10.1177/001316448304300141

\section{In Korean}

Bae, I. J., \& Wee, S, K. (2004). Relation of mother-teacher communication and social competence of preschool age children in kindergarten. Journal of Young Child Studies, 7, 25-47.

Bae, Y.-M., \& Cho, Y.-J. (2014). The study of preschool teacher's awareness of teacher-parent communication: Focusing on communication difficulties and self-efficacy. Early Childhood Education Research \& Review, 18(1), 323-340.

Baek, J. (2017). Self-regulation in early childhood: The role of sex, age, siblings and mother's domain-specific self-efficacy in parenting. Journal of Early Childhood Education, 37(5), 387-411. doi: 10.18023/kjece.2017.37.5.017

Chang, J. W., \& Hong, W.-H. (2005). Parent involvement for building partnership and mutual understanding between parents and teachers, The Journal of Educational Studies, 35(3), 47-64.

Choi, H. (2007). Working parent's recognition and demands for parent education and participation program (Master's thesis). Retrieved from http://www.riss.kr/link?id=T10908748

Choi, M., \& Park, Y. (2004). Mutual perception on teacher-mother communication in early childhood education center. The Journal of Korea Open Association for Early Childhood Education, 9(2), 137-160.

Chung, K.-S., Kim, M.-J., \& Ha, E.-S. (2012). The relationships between maternal happiness, parenting efficacy and egoresiliency of young children, Korea Open Association for Early Childhood Education, 17(1), 73-97.

Jang, S. O., \& Kim. Y.-M. (2011). Effects of maternal rearing stress and burnout on their parenting self-efficacy and parenting behaviors. Research of Waldorf Education, 3(1), 91-111.

Ju, H. (2002). Eorinijibeul iyonghaneun chwieommowa bichwieommoui boyugyokgu bigyo yeongu-seoulsi gangnamguni eorinijibeul jungsimeuro [어린이집을 이용하는 취업모와
비취업모의 보육욕구 비교 연구-서울시 강남구의 어린 이집을 중심으로] (Master's thesis). Retrieved from http:// www.riss.kr/link?id=T8199300

Jung, Y.-G. (2006). The present condition of communication between working mothers who use day care center and teachers, a degree of satisfaction, and a degree of requirement (Master's thesis). Retrieved from http://www.riss.kr/link?id=T10532517

Kim, A. R. (2010). Structure and application of combined on \& off-line parenting education programs or working mothers (Doctoral dissertation). Retrieved from http://www.riss.kr/ link?id=T11954319

Kim, H. L. (2003). A study on the understanding and needs of parents and teachers for parent - Education program in kindergarten (Master's thesis). Retrieved from http://www.riss.kr/ link?id=T9585150

Kim, H. M., \& Doh, H.-S. (2004). Maternal parenting stress, efficacy, and behavior: Relations to children's social competence. Korean Journal of Child Studies, 25(6), 279-298.

Kim, M.-J., Doh, H.-S., Shin, N. N., \& Choi, M.-K. (2013). The effects of preschoolers' temperament and parenting sense of competence on mothers' parenting behavior. Korean Journal of Child Studies, 34(2), 101-119. doi: 10.5723/ KJCS.2013.34.2.101

Kim, M. S., \& Moon, H. J. (2005). Relationship between parenting stress and parenting efficacy on parenting behaviors in mother with young children, Family and Environment Research, 43(8), 25-35.

Kim, N. H., Lee, E. J., Kwak, S. Y. \& Park, M. R. (2013). A phenomenological study on the experiences of parenting burden of working mother with young children in Korea. Korean Journal of Women Health Nursing, 19(3), 188-200.

Kim, Y.-H. (2004). A study on the effectiveness of the maternity training program for reducing the maternal guilt of working mothers - With special regard to the object relations theory (Doctoral dissertation). Retrieved from http://www.riss.kr/ link?id=T9721508

Kim, Y.-H., \& Park, J.-H. (2014). The relationship between teacher-child interaction and peer play behaviors among young children the moderating role of parent-teacher partnerships. Journal of Early Childhood Education, 34(3), 135-152.

Koo, S. J. (2001). The relation between kindergarten teachers' self-efficacy and communication level with parents (Master's thesis). Retrieved from http://www.riss.kr/ link?id=T8553499

Kwon, H. K. (2017). A study on father's and mother's parenting participation and parenting efficacy: Focusing on children's social competence. Journal of Korean Council for Children \& Rights, 21(1), 83-104. doi: 10.21459/kccr.2017.21.1.83

Lee, I.-H., Choi, S.-Y., \& Song, H.-W. (2013). The structural 
relationship among mother's parenting stress, parenting efficacy, parenting behavior and children's social competence, The Journal of Child Education, 22(1), 69-81.

Lee, J. A. (2012). Relationship of communication frequency and attitude between mothers and teachers (Master's thesis). Retrieved from http://www.riss.kr/link?id=T12907144

Lee, J.-Y. (2009). The relationships between parenting knowledge and parenting style of mothers with Infants: The mediating effect of parenting efficacy. Family and Environment Research, 47(5), 35-48.

Lee, K. H., \& Seo, S. J. (2012). The relationship between Infant temperament, maternal knowledge of infant development and infant development: The mediating effect of parenting self-efficacy. Journal of Future Early Childhood Education, 19(3), 53-77.

Lee, K. O., \& Lee, J. K. (1998). A study on the communication between mothers and teachers of kindergartners. Kyungsung University Bulletin, 19(1), 265-285.

Lee, M. J., \& Moon, H. J. (2008). Teacher-mother communication: Its effect on satisfaction with early childhood educational institutions and on parenting stress. Korean Journal of Child Studies, 29(1), 1-14.

Moon, Y. B., \& Choi, B. G. (2009). Analysis on the realities of parental involvement in the connecting activity family-child care center. Korean Journal of Child Education and Care, $9(2), 35-52$.

Park, B.-S. (1987). The study on children's social competence and the related variables (Master's thesis). Retrieved from http:// www.riss.kr/link?id=T869242

Park, Y. S. (2006). A study on the perception and demand of working mothers about parent's education in child care center (Master's thesis). Retrieved from http://www.riss.kr/link?id=T10286174

Roh, S.-K. (2012). A study on hindrance factors in teacher-parent communication between early childhood teachers and mothers. Korea Journal of Child Care and Education, 73, 211-232.

Sim, Y. (2013). Employed mothers's perception on parent involvement, focusing on day care center for employees in public institution. Journal of Early Childhood Education \& Educare Welfare, 17(2), 5-27.

Son, S.-R. (2008). Analysis of mutual perception for relationship between mother and teacher in the classes for 1, 2, 3 years old children at day-care centers (Master's thesis). Retrieved from http://www.riss.kr/link?id=T11390650

Song, Y. K., \& Hwang, S. H. (2013). Relationships between family participation in the early childhood education institution and variables on parents. The Research of Child Education and Care, 9(1), 65-82.

Sung, S.-Y. (2007). Parent-teacher communication in early childhood education- Why is it important for child care quality and parent-teacher partnership? The Journal of Social Sciences, 26(1), 383-400.

Sung, J. (2018). Relationship between maternal parenting efficacy and children's theory of mind: Mediating role of maternal autonomy and structure support. The Korean Journal of Development Psychology, 31(1), 151-171.

Sung, J., \& Baek, J. (2011). Validation of the echelle globale du sentiment de competence parentale(EGSCP) in Korea: A measure of domain-specific self-efficacy and related cognitive constructs for parents. The Korean Journal of Development Psychology, 24(4), 135-150.

Wee, S.-J. (2000). Research about mother-caregiver communication in kindergarten (Master's thesis). Retrieved from http://www. riss.kr/link?id=T9005099

Yeon, E. M., \& Choi, H. (2017). The effect of parent's sex-role attitude on parent-child relationship in multicultural families. Journal of the Korea Academia-Industrial Cooperation Society, 18(6), 171-179.

Yoon, S., \& Sung, J. (2014). The effects of mothers' parenting efficacy on children's emotional regulation: The role of mothers' perception of fathers' involvement in child care. Korean Journal of Child Studies, 35(4), 199-222. doi: dx.org/10.5723/KJCS.2014.35.4.199

Yu, H. J., \& Ahn, J. H. (2010). The relationship between teachermother communication and teachers' self-efficacy in child care centers. The Research of Child Education and Care, 6(2), $39-53$.

\section{ORCID}

Jiyoung Lee https://orcid.org/0000-0002-5531-6016

Jeehee Baek https://orcid.org/0000-0002-9589-9308

Jihyun Sung https://orcid.org/0000-0003-1149-6788

Received April 28, 2018

Revision received June 7, 2018

Accepted June 8, 2018 